\title{
Preliminary observations of the shear behaviour of fungal treated soil
}

\author{
Emmanuel Salifu ${ }^{1,2^{*}}$ and Gráinne El Mountassir ${ }^{1}$
}

${ }^{1}$ University of Strathclyde, Department of Civil and Environmental Engineering, Glasgow, UK

${ }^{2}$ Università di Napoli, Dipartimento di Ingegneria Civile, Edile e Ambientale, Federico II, Italy

\begin{abstract}
This paper presents results of an investigation into an entirely novel technique for ground improvement involving the use of fungal hyphae. Fungal hyphae (long filamentous branches) are known to contribute to soil aggregation and soil hydrophobicity, and are hypothesised to also influence the hydromechanical behaviour of soil. We present here preliminary observations of the mechanical behaviour of sands treated with the fungal species Pleurotus ostreatus (P. ostreatus). Direct shear tests were carried out on sand containing different percentages of organic substrate (the nutrient source for fungal growth) and treated with $P$. ostreatus. The stress-strain behaviour of fungal treated and untreated soil was investigated. Results show that irrespective of the percentage of organic matter, fungal treated specimens tended to show a loss in the peak behaviour characteristic of the untreated control specimens and an associated transition towards a more contractive volumetric response. The limited experiments conducted to date appear to indicate that the main factor responsible for the differences in behaviour between treated and untreated specimens is due to lubrication of the grains by the fungal hyphae and exudates. Further investigation is required to fully elucidate the mechanisms influencing the mechanical behaviour of fungal-treated soils.
\end{abstract}

\section{Introduction}

Within the emerging sub-discipline of bio-geotechnical engineering, [1] proposed a novel technique with a view to deploying it as a potential low-carbon technique for soil modification and ground improvement. Filamentous fungi (such as Pleurotus ostreatus) grow within nearsurface soil layers as a network of hyphae; this network is commonly referred to as the mycelium. These vegetative parts of the fungus develop from fungal spores or cells. Protein compounds in the cells are mobilised to one end, from where the cell extends structurally, forming a tubular elongated, thread-like shape (the hypha), which can fuse with adjacent hyphae or produce 'branches' capable of spreading over large areas and distances in environments where suitable conditions exist [2].

From the field of soil science, it is widely known that fungi present naturally in the environment contribute to soil architecture and soil aggregation (e.g. [3]). It is hypothesised that the growth of fungi can be engineered to bring about changes of geotechnical significance. The fungal characteristics of interest include their physical form. For filamentous fungi, that is the form of the hyphae or rhizomorphs which are typically $1-30 \mu \mathrm{m}$ in diameter and range from several microns up to metres in length, and can form extensive 3D hyphal networks. The physical action of the mycelium as it grows through the soil tends to enmesh or entangle soil grains, thereby contributing to the formation and maintenance of soil aggregates [3], [4].

The biochemical exudates released during the lifecycle of the fungus have also been found to influence soil wettability [5] and in an ecological community, tends to serve as a binding agent that contributes significantly to the enhancement of soil aggregate stability [6-8]. Soil aggregation and soil hydrophobicity are expected to affect soil water retention characteristics and hydro-mechanical behaviour. Fungal growth in soils requires the presence of organic matter as a nutrient source. As such the engineered growth of fungi in the field may require the addition of organic matter/nutrients.

This paper investigates for the first time, the shear behaviour of sands treated with fungi. The specific objectives of the study are: (i) to investigate the stressstrain behaviour of fungal-treated sands subjected to direct shear tests and compare with the untreated control specimens; and (ii) to investigate the influence of the percentage of amended organic matter.

\section{Materials and methods}

\subsection{Materials}

\subsubsection{Soil and lignocel}

\footnotetext{
${ }^{*}$ Corresponding author: emmanuel.salifu@strath.ac.uk
} 
Silica sand mixed with Lignocel ${ }^{\circledR}$ formed the composition of soil used in this study. Its characteristics are shown in Table 1. Lignocel (Grade HB 500 - 1000), a processed form of fibres derived from natural softwoods, is a commercially available organic material obtained from J. RETTENMAIER \& SÖHNE GmbH and was used as food source (substrate) for fungal growth in this study. The chemical constituents of lignocel typifies that of decaying organic matter in natural soils [9] and was deemed suitable for growing the saprophytic $P$. ostreatus used in this study. In all tests performed, sand and lignocel were sterilised prior to preparation of the specimens and inoculation with P.ostreatus by autoclaving at $121^{\circ} \mathrm{C}$ for 20 mins. The composition in terms of the percentage of sand and lignocel content (of the total mass of solids) for each specimen is given in Table 2 .

Table 1: Characteristics of sand and lignocel

\begin{tabular}{|c|c|c|c|}
\hline Properties & Sand & $\begin{array}{l}\text { Sand \& } \\
\text { lignocel }\end{array}$ & Lignocel \\
\hline $\mathrm{D}_{60}(\mathrm{~mm})$ & 0.33 & & Particle size \\
\hline $\mathrm{D}_{30}(\mathrm{~mm})$ & 0.28 & & range: \\
\hline $\mathrm{D}_{10}(\mathrm{~mm})$ & 0.2 & & $0.5-1 \mathrm{~mm}$ \\
\hline $\mathrm{C}_{\mathrm{c}}$ & 1.19 & & with \\
\hline $\mathrm{C}_{\mathrm{u}}$ & 1.65 & & $2 \%>1.25 \mathrm{~mm}$ \\
\hline $\begin{array}{c}\text { ASTM } \\
\text { classification }\end{array}$ & $\begin{array}{l}\text { Uniformly } \\
\text { graded } \\
\text { fine sand }\end{array}$ & - & $\begin{array}{c}65 \%>0.63 \mathrm{~m} ; \\
90 \%>0.5 \mathrm{~mm} \text {. } \\
\text { (from supplier's } \\
\text { data sheet) }\end{array}$ \\
\hline $\begin{array}{l}\text { Specific } \\
\text { gravity }\end{array}$ & 2.65 & 2.03 & \\
\hline
\end{tabular}

\subsubsection{Fungus}

P. ostreatus strain: M 2191 was used in this study and was obtained from GroCycle UK as active spawn (mycelia grown on a wheat substrate). The fungal spawn was stored in a cold room at $4^{\circ} \mathrm{C}$ and used within 30 days.

\subsection{Experimental procedures}

\subsubsection{Preparation of treatment additives}

Fungi grows by germination from its spores. A spore/hyphal suspension of $P$. ostreatus was prepared from spawn through a method developed by authors, as follows. Fresh spawn of known mass was collected, weighed and placed in a conical flask containing deionised water. This was then shaken vigorously by hand to ensure that spores and hyphae were released into the water. The mass ratio of spawn:water was $1 \mathrm{~g}: 10 \mathrm{~mL}$. The mixture was then further shaken at $320 \mathrm{rpm}$ for $30 \mathrm{mins}$ and then filtered through a $2 \mathrm{~mm}$ sieve to remove larger spawn residues. The filtrate obtained is a suspension containing both harvested spores and hyphae. This was the liquid treatment added to the fungal-treated (T) specimens.

Fungal homogenate $(\mathrm{FH})$ was also prepared for a set of experiments (section 3.3) from actively growing spawn, following a similar method described in CaesarTonThat and Cochran (2000). A fixed mass of sclerotia (thick spongy mass formed by older mycelia) extracted from the exterior of a 25 - 30day old spawn was obtained, aseptically crushed by hand and blended to bits. This was added to DI water ( mix ratio $=2 \mathrm{~g}$ sclerotia bits: $1 \mathrm{~mL}$ DI water) and homogenised using a sonicator for 20 mins. The mixture was filtered through a $2 \mathrm{~mm}$ sieve to remove solid bits leaving a cloudy-watery-suspension or filtrate, the homogenate. Compared to the hyphal/spore suspension described above the homogenate contains a higher concentration of fungal biomass and exudates.

Table 2: Test specimens: composition and test conditions

\begin{tabular}{|c|c|c|c|c|}
\hline Specimen & $\begin{array}{l}\text { Normal } \\
\text { stress } \\
(\mathrm{kPa})\end{array}$ & $\begin{array}{l}\text { Sand } \\
(\%)\end{array}$ & $\begin{array}{l}\text { Lignocel } \\
(\%)\end{array}$ & $\begin{array}{c}\text { Liquid } \\
\text { content } \\
(\%)\end{array}$ \\
\hline $\mathrm{T}-25 \mathrm{kPa}$ & 25 & 94 & 6 & 11 \\
\hline $\mathrm{U}-25 \mathrm{kPa}$ & 25 & 94 & 6 & 11 \\
\hline $\mathrm{T}-50 \mathrm{kPa}$ & 50 & 94 & 6 & 11 \\
\hline $\mathrm{U}-50 \mathrm{kPa}$ & 50 & 94 & 6 & 11 \\
\hline $\mathrm{T}-100 \mathrm{kPa}$ & 100 & 94 & 6 & 11 \\
\hline $\mathrm{U}-100 \mathrm{kPa}$ & 100 & 94 & 6 & 11 \\
\hline T_94:6LIG & 25 & 94 & 6 & 11 \\
\hline U_94:6LIG & 25 & 94 & 6 & 11 \\
\hline T_70S:30LIG & 25 & 70 & 30 & 11 \\
\hline U_70S:30LIG & 25 & 70 & 30 & 11 \\
\hline T_50S:50LIG & 25 & 50 & 50 & 11 \\
\hline U_50S:50LIG & 25 & 50 & 50 & 11 \\
\hline UFH_94:6LIG & 25 & 94 & 6 & 11 \\
\hline $\begin{array}{c}\text { TFH_94:6LIG } \\
(\text { Day 0) }\end{array}$ & 25 & 94 & 6 & 11 \\
\hline $\begin{array}{l}\text { TFH_94:6LIG } \\
\text { (1 month) }\end{array}$ & 25 & 94 & 6 & 11 \\
\hline
\end{tabular}

\subsubsection{Specimen preparation}

Each treated specimen was composed of sand, lignocel and spore/hyphal suspension. For the untreated (control) specimens the volume of spore/hyphal suspension was replaced with deionised water. The liquid content (spore/hyphal suspension or deionised water) is presented in Table 2 for each test specimen and is determined as the mass of liquid/mass of solids.

After mixing, the soil-lignocel-liquid mixture was lightly compacted into plastic moulds (Fig. 1). Multiple plastic moulds were manufactured using an 'Ultimaker' Extended' 3D printer. Multiple random pin-holes were perforated on the sides of the mould to allow passage of oxygen into the specimen. These moulds were required to 
enable growth in multiple test specimens over 3 weeks under controlled environmental conditions. The hollow square-shaped moulds had outer dimensions of $58.97 \mathrm{x}$ $58.97 \times 40 \mathrm{~mm}$ and wall thickness of $0.5 \mathrm{~mm}$ to facilitate minimal disturbance of the specimen when transferred to the shear box for testing.

Specimens were prepared with dry densities in the range of $0.9-1.1 \mathrm{~g} \mathrm{~cm}^{-3}$ to ensure adequate porosity and thus aeration. All specimens were incubated at $25^{\circ} \mathrm{C}$ in the dark and taken out for shear testing after the growth period of 3 weeks. After assembling the specimens in the shear box, the specimens were inundated with water and left for 2 hours prior to testing.

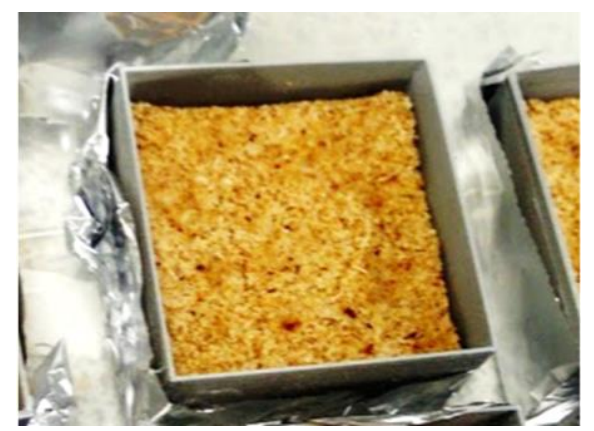

Fig. 1. Specimen lightly compacted into plastic mould before incubation

\subsubsection{Direct shear test}

A digital direct shear test apparatus (ELE International, UK) with a load cell of $5 \mathrm{kN}$ capacity was used in this study. It has a $60 \mathrm{~mm}$ square shear box and is equipped with two displacement transducers for monitoring both horizontal and vertical displacements. The apparatus was connected to a computer for data acquisition via a LabVIEW ${ }^{\circledR}$ programme interface. Specimens were tested at normal stresses of $25 \mathrm{kPa}, 50 \mathrm{kPa}$ and $100 \mathrm{kPa}$ Specific test conditions of each specimen are listed in Table 2. All specimens were sheared at a shearing rate of $1 \mathrm{~mm} / \mathrm{min}$.

\subsubsection{Determination of fungal presence after shear tests}

To investigate the presence of fungi in the specimens after shearing, the sheared surfaces of selected specimens were stained using fluorescein diacetate (FDA) and acridine orange (AO). FDA glows green under UV light when viable (i.e. living cells) are present, indicating the presence of live fungi. AO on the other hand stains and fluoresces varied intensities of green-yellow-red depending on stages of fungal colonisation and indicating when live or dead fungal-hyphae are present [10].

\section{Results and discussion}

\subsection{Visual observations}

It was visibly evident that for the fungal treated specimens, the presence of the fungal growth resulted in binding of the test specimen components. As such for the treated specimens it was possible to transfer the specimens directly into the shear box from the plastic mould using a pushing tool. In this procedure the fungal treated specimens remained intact (as a whole specimen) with minimal disturbance. On the other hand, during transfer of the untreated control specimens (which were also initially placed in the plastic moulds and in the controlled environment for 3 weeks) via the same procedure it was clear that the control specimens remained composed of cohesionless loose sand/lignocel. As such these specimens were recompacted into the shearbox with the same procedure as during initial preparation with the aim of achieving the same initial target dry density $\left(0.9-1.1 \mathrm{gcm}^{-3}\right)$.

Fig. 2 shows the shearing plane of typical treated samples stained with FDA (on the right) and AO (on the left). The FDA-stained samples did not give off the green glow but with the AO stain, the samples showed a clear fluorescence implying that fungal cells and what appear to be hyphae are present but are no longer live. It is possible that as these samples were taken from the shear plane, the mechanical action may have ruptured hyphae and cells.

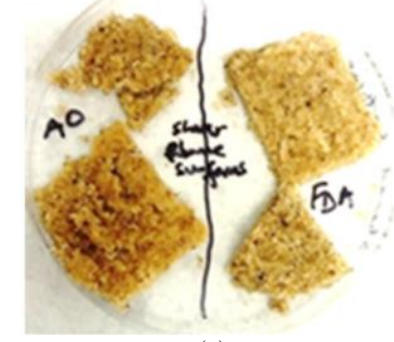

(a)

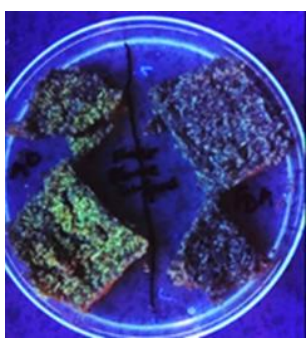

(b)
Fig. 2. Samples of sheared surfaces (a) before and (b) after staining with FDA (to right) and AO (to left).

\subsection{Effect of fungal treatment on shear properties}

Figs. 3a-c show plots of shear stress and vertical displacement against horizontal displacement as well as the failure envelope for treated and untreated specimens under applied normal loads of 25,51 and $100 \mathrm{kPa}$. It is evident in Figure $3 \mathrm{a}$ that the fungal treated specimens do not exhibit the same peak shear behaviour observed in the untreated control specimens. Accordingly, Fig. 3b indicates that the untreated specimens all exhibited dilatant behaviour, whereas the treated specimens exhibited contractive behaviour. 


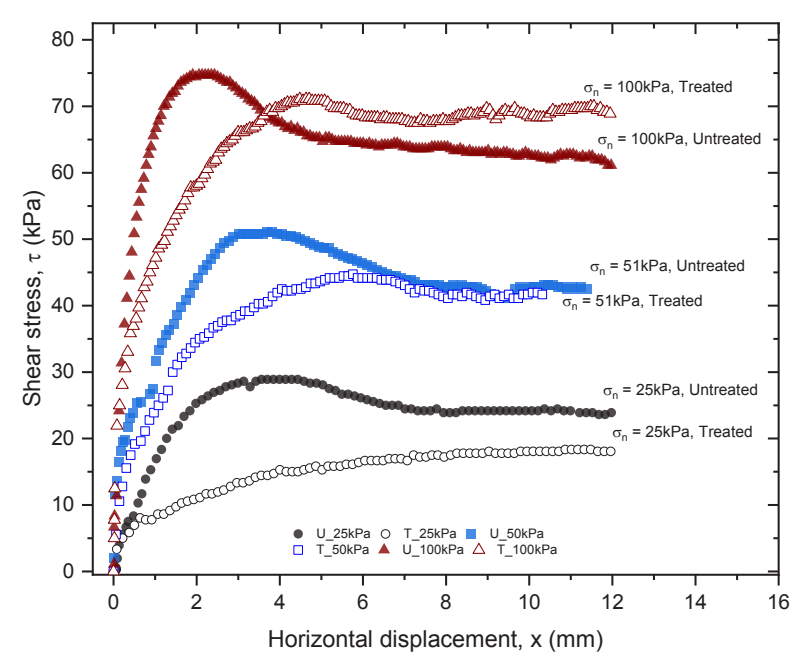

(a)

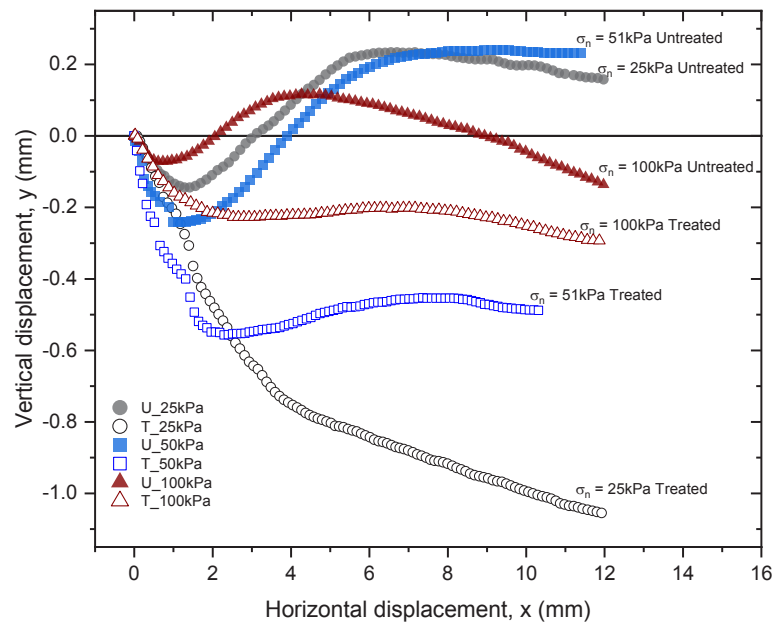

(b)

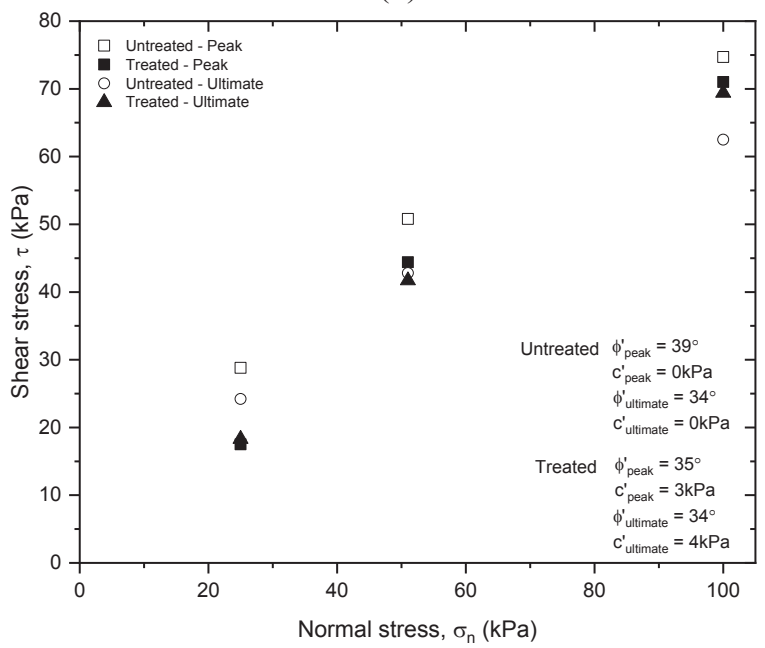

(c)

Fig. 3. (a) Shear stress - horizontal displacement and (b) volumetric behaviour of treated and untreated soils under applied normal stresses of 25,51 and $100 \mathrm{kPa}$; (c) failure envelope of treated and untreated soil

As seen in Fig. 3c, the peak friction angle $\left(\phi^{\prime}\right.$ peak $)$ decreased from $39^{\circ}$ for untreated specimens to $35^{\circ}$ for treated specimens, while the ultimate $\phi^{\prime}$ ultimate was approx. $34^{\circ}$ for both treated and untreated specimens. Cohesion (c') for the peak and ultimate failure envelopes for treated specimen were $\mathrm{c}_{\text {peak }}^{\prime}=3 \mathrm{kPa}$ and $\mathrm{c}_{\text {ultimate }}^{\prime}=4 \mathrm{kPa}$ respectively.

The reduction/removal of the peak shear strength observed in the fungal treated sands may be a result of a number of possible factors: (i) The enmeshment of the sand and lignocel grains by the fungal hyphae created a stiffer specimen, with the consequence that on the application of the vertical stress the presence of the hyphal network prevented the sand/lignocel grains from rearranging to the same extent as in the untreated specimens. Thus despite having the same initial dry density, after applying the vertical stress, the treated specimens likely maintained a lower dry density and more open structure compared to the untreated specimens. In early trials larger vertical displacements were recorded for treated specimens compared to untreated specimens during loading. Unfortunately this data is not available for the test specimens presented in this paper. (ii) It is proposed that the fungal hyphae, which are composed of chitin, i.e. polysaccharides and any additional exudates released by $P$. ostreatus as it grows may act as a 'lubricant' reducing the potential for interlocking of the sand grains and thus lower the frictional resistance in the treated specimens. (iii) As the fungus grows, lignocel is digested as the nutrient source, thus it is possible that this is also partly responsible for a lower dry density in the fungal treated specimens (compare to the untreated) immediately prior to shearing.

\subsection{Effect of amount of organic matter on shear behaviour of treated soil}

Treated and untreated soil made up of variable proportions of lignocel and sand (see Table 2) were investigated. This was based on the hypothesis that increasing the amount of organic matter added to soil would affect fungal growth and by extension may influence the soil shear behaviour. Fig. $4 \mathrm{a}$ and $\mathrm{b}$ show the plots for shear stress and vertical displacement against horizontal displacement for both treated and untreated specimens with the amount of lignocel (LIG) ranging from $6-50 \%$. The results show a similar reduction/loss of the peak behaviour for treated specimens as seen in section 3.1 above. For all untreated specimens, dilative behaviour was maintained and, the treated specimens, exhibited contractive behaviour. As the \% of LIG increased from $6-50 \%$ shear resistance increased in both the treated and untreated specimens. Given that the 'particle' size of lignocel is larger than that of the sand grains (see Table 1) and that the shape of the lignocel is cuboid in nature (rather than spherical), this can be considered to be due to the increased opportunity for interlocking with an increasing percentage of lignocel. 

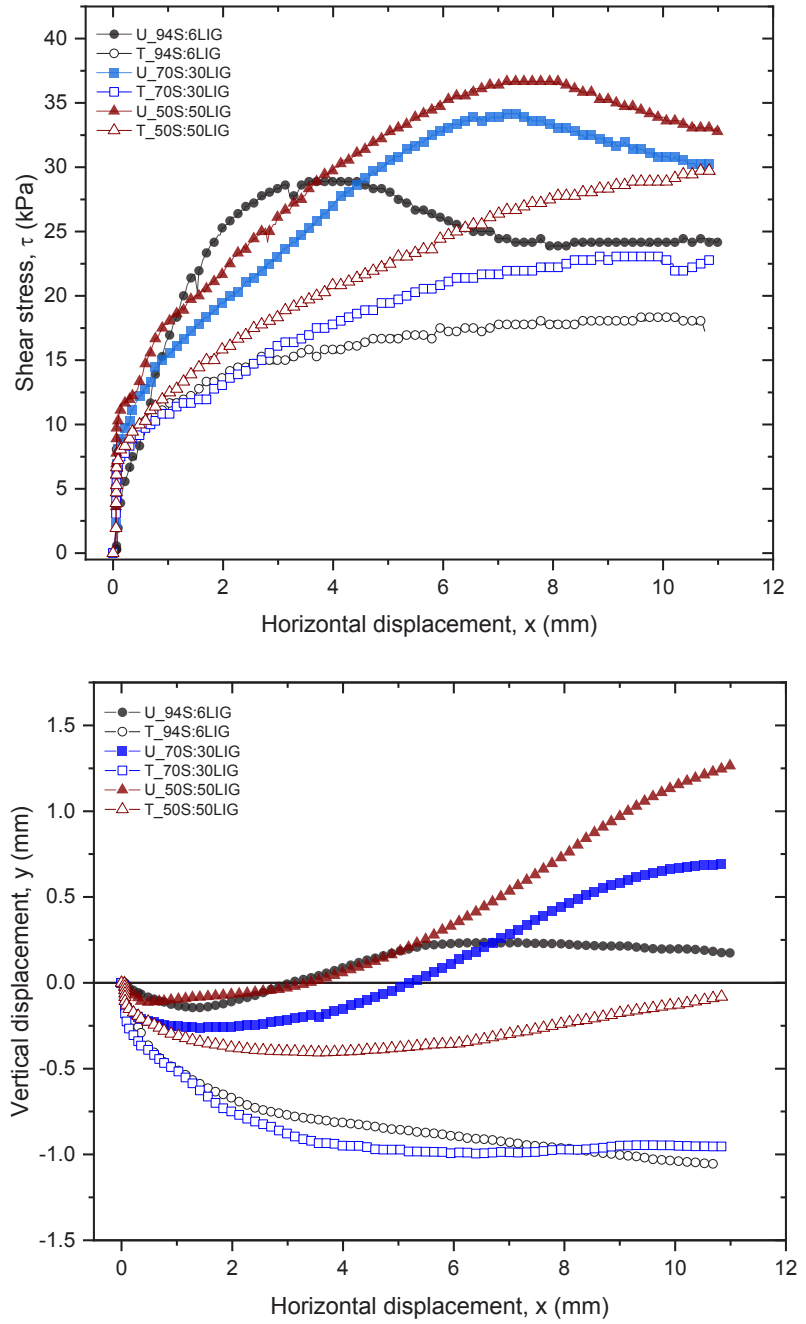

Fig. 4. Shear stress and volumetric change for treated and untreated specimens with varied amounts of LIG

\subsection{Influence of growth duration on shear behaviour}

In order to determine which factors are likely responsible for the difference in behaviour observed between untreated and treated specimens in 3.1 and 3.2, a series of experiments were conducted on specimens prepared with fungal homogenate, one was tested in the shear box immediately after mixing and assembling (i.e. no opportunity for hyphae to enmesh soil grains, and one was left for a growth duration of one month (possibility for hyphal growth and enmeshment). Both are compared to an untreated control specimen in Figure 5. There is a large reduction in the peak shear strength even on Day 0 . This suggests that this loss in shear strength is not due to hyphal growth enmeshing grains and creating a stiffer overall specimen, more resistant to densification on loading. Furthermore for the specimen tested on Day 0, it is proposed that no/minimal fungal growth would have occurred in-situ and therefore lignocel would not have been digested in such a time frame, as to be responsible for the change in behaviour observed. These results therefore appear to lend support for the theory that the change in behaviour is primarily due to lubrication of the grains by the materials composing the fungal homogenate (i.e. chitin and exudates).
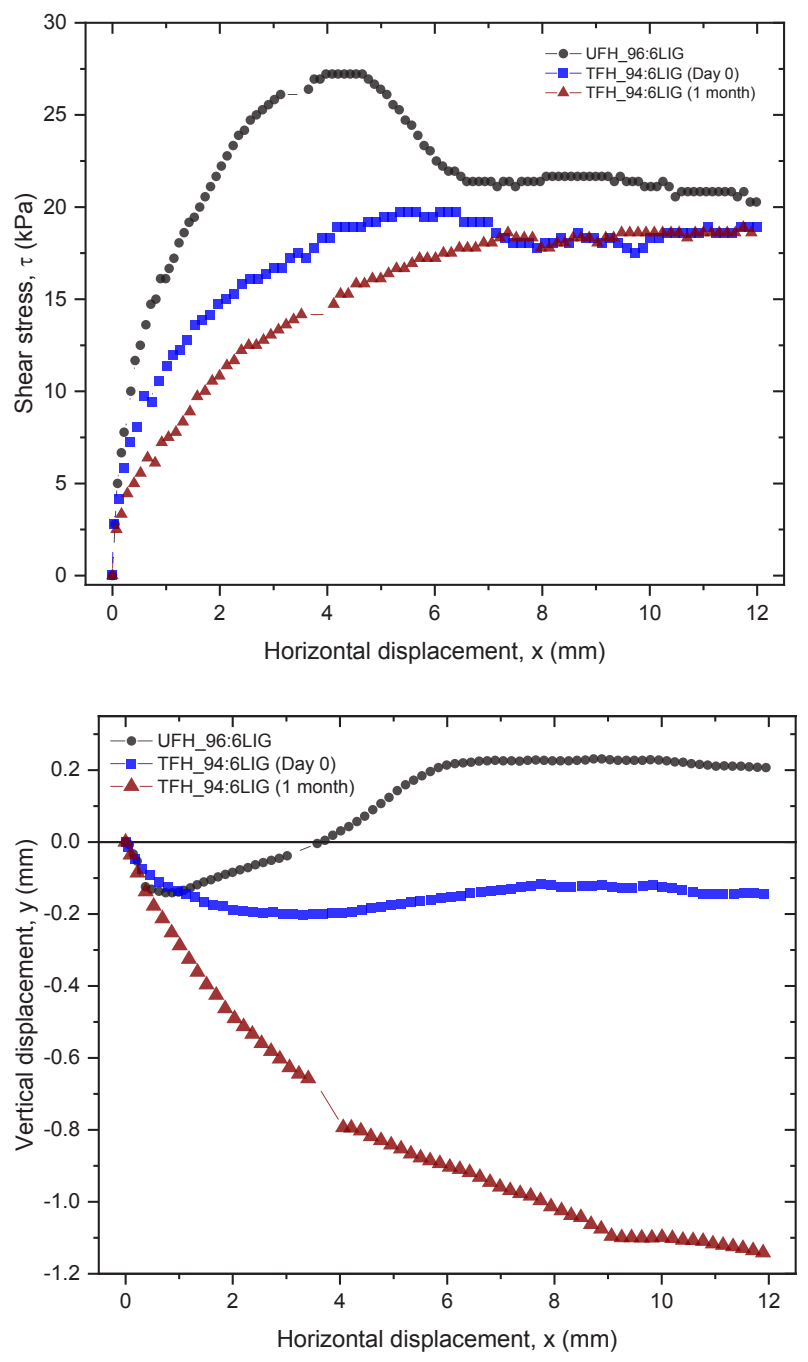

Fig. 5. Shear stress-horizontal displacement and volumetric change for untreated specimen and specimens treated with homogenate $\&$ tested immediately after mixing (day 0 ) and 1 month after.

\section{Discussion and conclusion}

This paper presented the first investigation into the stressstrain behaviour of fungal treated soils tested under direct shear conditions. It is evident from the experiments conducted that a loss in peak shear strength was observed and an associated contractive volumetric behaviour. The limited experiments conducted to date appear to indicate that under the stress levels investigated and in the test procedure adopted herein the main factor responsible for the differences in behaviour between treated and untreated were due to lubrication of the grains by the hyphae and exudates. Further investigation is required to fully elucidate the mechanisms influencing the mechanical behaviour of fungal-treated soils.

It is acknowledged that this study is the first attempt to characterise this type of bio-geotechnical sample and as such a number of modifications in the experimental method are suggested and recommendations for further 
studies are given here: (i) Inoculate and allow for fungal growth directly in specimens mounted in the shear box and already loaded to the desired vertical stress. This would eliminate any disturbance of specimens due to transferring from the mould. Furthermore, it is possible that any effect of hyphal enmeshment has been minimised in this study due to loading of the specimen after hyphal growth, such that the hyphae become slack on loading and thus do not contribute to the overall shear strength of the specimen. (ii) Use organic matter in powder/liquid form instead of large fibres like lignocel, whose physical form also influenced the resulting stress-strain behaviour, (iii) Conduct tests at lower normal stresses which may be more applicable to the contexts of interest, e.g. interface applications; and (iv) investigate the influence of increasing treatment duration.

The authors wish to acknowledge the support of the European Commission via the Marie Skłodowska-Curie Innovative Training Networks (ITN-ETN) project TERRE 'Training Engineers and Researchers to Rethink geotechnical Engineering for a low carbon future' (H2020-MSCA-ITN-2015-675762) and the the Engineering and Physical Sciences Research Council via Grant EP/N035526/1.

\section{References}

1. G. El Mountassir, J. M. Minto, L. A. van Paassen, E. Salifu, R. J. Lunn, App. of Microbial Proc. in Geotech. Eng., 104, 1 (2018)

2. M. L. Smith, J. N. Bruhn, J. B. Anderson, Nature, 356, 6368, 428-431 (1992)

3. M. C. Rillig, Can. J. Soil Sci., 84, 4, 355-363, (2004)

4. T. C. Caesar-TonThat,V. L. Cochran, Biol. Fertil. Soils, 32, 5, 374-380 (2000)

5. A. Liu, B. L. Ma, A. A. Bomke, Soil Sci. Soc. Am. J., 69, 2041-2048 (2005)

6. V. L. Baumert, N. A. Vasilyeva, A. A. Vladimirov, I. C. Meier, I. Kögel-Knabner, C. W. Mueller, Front. Environ. Sci., 6 (2018)

7. M. I. Rashid, L. H. Mujawar, T. Shahzad, T. Almeelbi, I. M. I. Ismail, M. Oves, Microbiol. Res., 183, 26-41 (2016)

8. J. Tang, Y. Mo, J. Zhang, R. Zhang, Appl. Soil Ecol., 47, 3, 153-159 (2011)

9. A. Imran, E. A. Bramer, K. Seshan, G. Brem, Energies, 9, 3, 1-17 (2016)

10. C. J. Houtman, P. Kitin, J. C. D. Houtman, K. E. Hammel, C. G. Hunt, PLoS One, 11, 7, 1-19 (2016) 